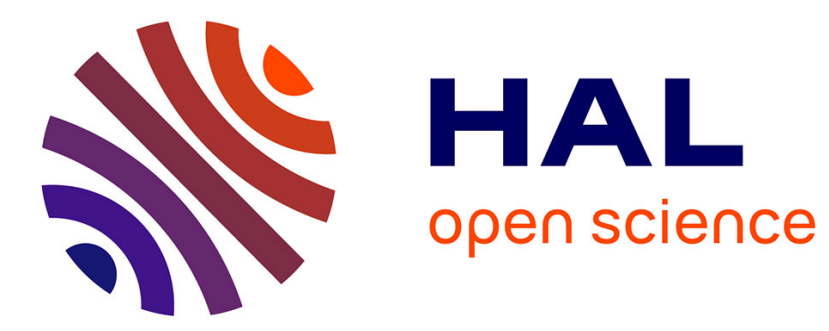

\title{
Optimal bone structure is dependent on the interplay between mechanics and cellular activities
} Jamie C Frame, Pierre-Yves Rohan, Laurent Corte, Rachele Allena

\section{To cite this version:}

Jamie C Frame, Pierre-Yves Rohan, Laurent Corte, Rachele Allena. Optimal bone structure is dependent on the interplay between mechanics and cellular activities. Mechanics Research Communications, 2018, 92, pp.43-48. 10.1016/j.mechrescom.2018.07.005 . hal-02370909

\section{HAL Id: hal-02370909 \\ https://hal.science/hal-02370909}

Submitted on 19 Nov 2019

HAL is a multi-disciplinary open access archive for the deposit and dissemination of scientific research documents, whether they are published or not. The documents may come from teaching and research institutions in France or abroad, or from public or private research centers.
L'archive ouverte pluridisciplinaire HAL, est destinée au dépôt et à la diffusion de documents scientifiques de niveau recherche, publiés ou non, émanant des établissements d'enseignement et de recherche français ou étrangers, des laboratoires publics ou privés. 


\title{
Optimal bone structure is dependent on the interplay between mechanics and cellular activities
}

\author{
Jamie C. Framea, Pierre-Yves Rohan ${ }^{\mathrm{a}, *}$, Laurent Corté ${ }^{\mathrm{b}, \mathrm{c}}$, Rachele Allena ${ }^{\mathrm{a}}$ \\ ${ }^{a}$ LBM/Institut de Biomécanique Humaine Georges Charpak, ENSAM Paris, France \\ b Centre des Matériaux CNRS: UMR7633, MINES ParisTech, PSL Research University, France \\ ${ }^{\mathrm{c}}$ Matiére Molle et Chimie CNRS: UMR 7167, ESPCI Paris, PSL Research University, France
}

Keywords:

Bone remodeling

Femur

FE simulation

Mechano-biology

Mechanostat

\begin{abstract}
A B S T R A C T
Bone is a tissue with the remarkable capacity to adapt its structure to an optimized microstructural form depending on variations in the loading conditions. The remodeling process in bone produces distinct tissue distributions such as cortical and trabecular bone but also fibrous and cartilage tissues. Although it has been demonstrated that mechanical factors play a decisive role in the architectural optimization, it may also follow that biological factors have an influence. This interplay between loading and physiology has not been previously reported but is paramount for a proper assessment of bone remodeling outcomes. In this work we present a mechanostat model for bone remodeling which is shown to predict the mechanically driven homeostasis. It is further demonstrated that the steady-state reached is innately dependent upon the loading magnitudes and directions. The model was then adjusted to demonstrate the influence of specific biological factors such as cell proliferation, migration and resorption. Furthermore, two scenarios were created to replicate the physiological conditions of two bone disorders - osteoporosis and osteopetrosis - where the results show that there is a significant distinction between the homeostatic structures reached in each case and that the tissue adaptations follow similar trends to those observed in clinical studies.
\end{abstract}

\section{Introduction}

Bone is a highly adaptable tissue which has the capacity to uniquely alter its architecture and morphology to the surrounding loading conditions [1-6]. The biological processes of resorption and formation of old and new bone through the lifespan of the tissue operate continually to drive bone remodeling from the micro to the macro scales. Cortical and trabecular bone clearly show this difference in structural optimization of bone density distribution where the highly stressed and densely mineralized cortical regions around the exterior of long bones contrast with the observably less dense but equally structurally optimized internal cancellous regions. Localized stress and strain are believed to determine the remodeling processes of bone resorption and formation $[4,7-10]$ and the homeostasis reached in bone has been suggested to follow the theory of the mechanostat [11]. Several numerical models describe the unique cellular [12-14], mechano-biological [9,14-16] and mechano-biochemical [17-19] processes involved in bone remodeling, all of which are unified by the underlying load-

\footnotetext{
* Corresponding author.

E-mail address: pierre-yves,rohan@ensam.eu (P.-Y. Rohan).
}

ing control of each biological process. The inclusion of a loading range where remodeling does not occur - or a 'lazy zone' - in the mechanostat model $[3,20]$, has given rise to the problem of uniqueness of the solution independent of the initial conditions [21-23]. Conversely, there is evidence that the mechanostat follows a parabolic strain controlled remodeling trend without a lazy zone $[13,24,25]$. The continual alteration of bone structure from the cellular scale upwards lends itself to the theory that bone tissue density is structurally optimized to the loading environment. Recently, Goda et al. have demonstrated that a femur shape may be predicted using structural topology optimization of bone mineral density [5]. However, being able to predict the response of bone tissue to adaptations in the mechanical stimulation [26,27] or biological factors such as bone diseases [28-31] is vital in understanding and predicting the final structural architecture. This is of particular significance when considering the integration of an implant and the surrounding remodeling of the existing bone tissue.

In this work, based on the mechano-biological framework we proposed in [32], the optimized tissue distribution of the internal structure (i.e. cortical and trabecular bone) of a proximal femur as a function of both the externally imposed loading and the cellular activities is predicted. Additionally, by altering specific biologi- 
cal parameters, we are able to describe different physiological and pathological scenarios.

The paper is organized as follows: in Section 2 the analytical and numerical frameworks used to develop the remodeling model are presented. This same section further presents the numerical simulations implemented to investigate the influence of the loading and biology, as well as two specific physiological bone disorders, on the structural steady-state of a proximal femur. In Section 3, the results from the numerical simulations are presented. Section 4 provides a discussion and conclusion on the findings.

\section{Material and methods}

\subsection{PDEs for immature and mature tissue development}

In this section we briefly recall the main equations driving the mechanobiological framework we proposed in [32].

We consider the evolution of bone tissue in the immature and mature states. The distinction between immature and mature tissues provides a description of primary and secondary mineralization $[33,34]$. Therefore, the total tissue volume fraction $\phi_{\text {TOT }}$ is decomposed as the sum of immature $\left(\phi^{I}\right)$ and mature $\left(\phi^{M}\right)$ tissue volume fractions:

$\varphi_{\text {TOT }}=\varphi^{I}+\varphi^{M}$

The local volume fraction of unfilled space is given by: $\phi_{V}=\left(1-\phi_{\text {TOT }}\right)$, where $\phi_{\text {TOT }} \leq 1$.

The evolution of the immature tissue is dependent on four specific terms: cell migration, cell proliferation, resorption (describing the resorption of cells and removal of matrix) and the transformation of immature tissue into mature tissue through maturation. A diffusion-reaction equation describes these processes as follows:

$$
\begin{aligned}
& \frac{\partial \varphi^{I}}{\partial t}=\overbrace{\left(1-\varphi_{\text {TOT }}\right) \boldsymbol{D} \Delta \varphi^{I}}^{\text {Mesorption }}+\overbrace{\alpha\left(1-\varphi_{\text {TOT }}\right) \varphi_{\text {TOT }}\left(T^{P}\right)}^{\text {Proliferation }} \\
& -\overbrace{\beta \varphi^{I}\left(T^{R}\right)}^{\text {Resorption }}-\overbrace{\gamma \varphi^{I}\left(T^{M}\right)}^{\text {Maturation }}
\end{aligned}
$$

where the tensor $\boldsymbol{D}$ reads

$\left.D=\lambda I+\Phi \sqrt{\left|\varepsilon_{I}\right|} \boldsymbol{\theta}_{\boldsymbol{I}} \otimes \boldsymbol{\theta}_{\boldsymbol{I}}+\sqrt{\left|\varepsilon_{I I}\right|} \boldsymbol{\theta}_{\boldsymbol{I I}} \otimes \boldsymbol{\theta}_{I I}\right)$

with $\lambda$ and $\Phi$ specific constants, $\boldsymbol{I}$ the identity matrix, $\varepsilon_{I}$ and $\varepsilon_{I I}$ and $\boldsymbol{\theta}_{\boldsymbol{I}}$ and $\boldsymbol{\theta}_{\boldsymbol{I I}}$ the principal strains and directions, respectively and $\otimes$ indicating the tensorial product. The corrective factor $\left(1-\varphi_{T O T}\right)$ accounts for the fact that migration and proliferation can only take place in the remaining unfilled volume fraction.

In the model, cellular growth occurs in both mature and immature tissues. Therefore, proliferation scales with $\varphi_{\text {TOT }}$ and a specific rate coefficient $\alpha$. Resorption and maturation both lead to a decrease in immature tissue content. They linearly scale with $\varphi^{I}$ and with the rate coefficients $\beta$ and $\gamma$ for resorption and maturation, respectively. All rate coefficients are positive.

Mature tissue is created by maturation from immature tissue and can only be removed by resorption. Accordingly, the evolution of mature tissue volume fraction is defined by a reaction equation as:

$\frac{\partial \varphi^{M}}{\partial t}=\overbrace{\gamma \varphi^{I}\left(T^{M}\right)}^{\text {Maturation }}-\overbrace{\beta \varphi^{M}\left(T^{A}\right)}^{\text {Resorption }}$

The functions $T^{P}, T^{A}$ and $T^{M}$ define the proliferation, resorption and maturation for different ranges of accumulated strain. A full description of these functions and the associated mechanostat is given in [32]. For Eqs. (2) and (4) a zero flux boundary condition is applied on free surfaces.
Table 1

The material properties for Bulk and shear moduli of the immature and mature tissues.

\begin{tabular}{llll}
\hline Variable & Symbol & Value & Unit \\
\hline Immature tissue bulk modulus & $K^{I}$ & $1.67 \mathrm{E} 7$ & $\mathrm{~Pa}$ \\
Immature tissue shear modulus & $G^{I}$ & $3.57 \mathrm{E} 6$ & $\mathrm{~Pa}$ \\
Mature tissue bulk modulus & $K^{M}$ & $1.52 \mathrm{E} 10$ & $\mathrm{~Pa}$ \\
Mature tissue shear modulus & $G^{M}$ & $7.81 \mathrm{E} 9$ & $\mathrm{~Pa}$ \\
\hline
\end{tabular}

(a)

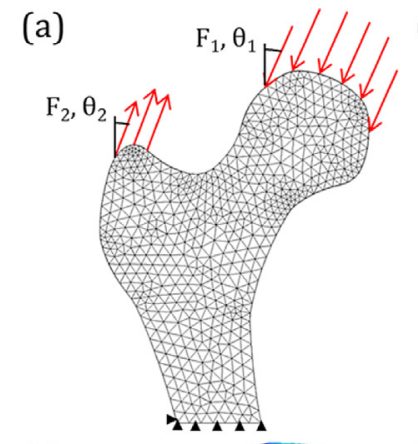

(b)

(d)

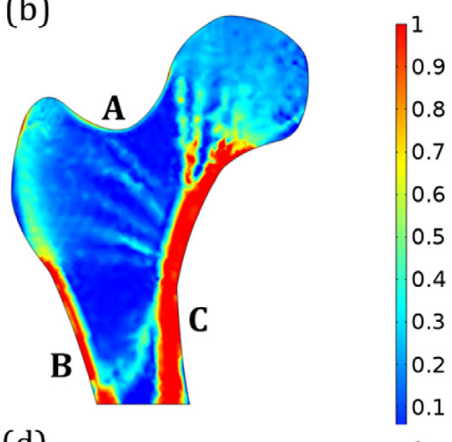

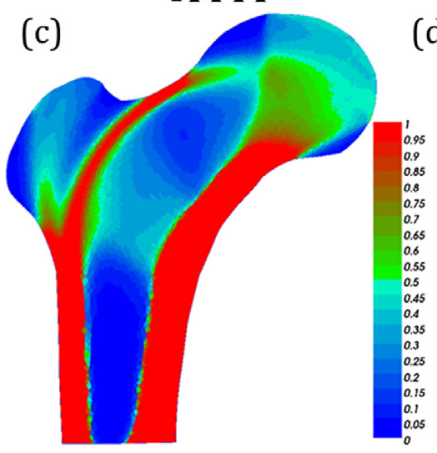

Fig. 1. (a) The loading, boundary conditions and mesh used in the simulations (b) a plot of the normalized Young's modulus showing the homeostasis reached after $10,000 \mathrm{~h}$ of simulated time for the initial mature bone volume fraction of 0.25 (c) the optimized bone density distribution found by Goda et al. [5] (d) roentgenogram of the internal structure of the femur from Goda et al. [5].

Hooke's law was used to provide a linear isotropic elastic relationship between stress and strain and mechanical equilibrium is achieved by:

$\operatorname{Div} \boldsymbol{\sigma}+\boldsymbol{f}=0$

where $\boldsymbol{\sigma}$ is the Cauchy's stress tensor and $\boldsymbol{f}$ are the body loads.

Finally, to combine the linear elastic isotropic material models, in both the immature and mature state, a simple upper bound composite description has been chosen for the local bulk and shear moduli, $K_{\text {TOT }}$ and $G_{T O T}$ :

$K_{T O T}=\varphi^{I} K^{I}+\varphi^{M} K^{M}$

$G_{T O T}=\varphi^{I} G^{I}+\varphi^{M} G^{M}$

where $K^{I}, K^{M}, G^{I}$ and $G^{M}$, are the bulk and shear moduli of the immature and mature tissue components, respectively. The values chosen are detailed in (Table 1) [33,35-37].

\subsection{Numerical applications}

A proximal femur geometry was created using B-splines and meshed using lower order triangular elements (Fig. 1a). Three preliminary simulations were undertaken with initially uniform volume fractions of mature bone set to levels of $0.25,0.5$ and 0.75 and an initial uniform immature bone volume fraction of 0.1 for each variation (Table 2 - Set 1 ). Constant loading was applied to 
Table 2

Initial conditions and rate coefficients used in each simulation.

\begin{tabular}{|c|c|c|c|c|c|c|c|c|c|c|c|}
\hline Set & Simulation & $\varphi_{B}^{I}$ & $\varphi_{B}^{M}$ & $F_{1}(\mathrm{~N})$ & $F_{2}(\mathrm{~N})$ & $\theta_{1}$ & $\theta_{2}$ & $\alpha_{B}\left(\mathrm{~m}^{2} \mathrm{~s}^{-1}\right)$ & $\beta_{B}\left(\mathrm{~m}^{2} \mathrm{~s}^{-1}\right)$ & $\gamma_{B}\left(\mathrm{~m}^{2} \mathrm{~s}^{-1}\right)$ & $\Phi_{B}\left(\mathrm{~m}^{2} \mathrm{~s}^{-1}\right)$ \\
\hline \multirow[t]{3}{*}{ Set 1} & A (control) & 0.1 & 0.25 & 2317 & 703 & $24^{\circ}$ & $28^{\circ}$ & $4 e-6$ & $1 e-7$ & $2 e-6$ & $1 e-8$ \\
\hline & B & 0.1 & 0.5 & & & & & & & & \\
\hline & $\mathrm{C}$ & 0.1 & 0.75 & & & & & & & & \\
\hline \multirow[t]{2}{*}{ Set 2} & A & 0.1 & 0.25 & 2317 & 703 & $14^{\circ}$ & $18^{\circ}$ & $4 e-6$ & $1 e-7$ & $2 e-6$ & $1 e-8$ \\
\hline & B & & & 1545 & 469 & & & & & & \\
\hline \multirow[t]{8}{*}{ Set 3} & A & 0.1 & 0.25 & 2317 & 703 & $24^{\circ}$ & $28^{\circ}$ & $6 e-6$ & $1 e-7$ & $2 e-6$ & $1 e-8$ \\
\hline & B & & & & & & & $2.67 e-6$ & & & \\
\hline & $\mathrm{C}$ & & & & & & & $4 e-6$ & $1.5 e-7$ & & \\
\hline & $\mathrm{D}$ & & & & & & & & $0.67 e-7$ & & \\
\hline & $\mathrm{E}$ & & & & & & & & $1 e-7$ & $3 e-6$ & \\
\hline & $\mathrm{F}$ & & & & & & & & & $1.33 e-6$ & \\
\hline & G & & & & & & & & & $2 e-6$ & $1.5 e-8$ \\
\hline & $\mathrm{H}$ & & & & & & & & & & $0.67 e-8$ \\
\hline
\end{tabular}

each of these three simulations for a simulated time of $10,000 \mathrm{~h}$, replicating the loading applied in similar bone remodeling simulations $\left(F_{1}=2317 \mathrm{~N}, \theta_{1}=24^{\circ}\right.$ and $F_{2}=703 \mathrm{~N}, \theta_{2}=28^{\circ}$ Fig. 1$)$ [5,7], where $F_{1}$ represents the joint reaction force and $F_{2}$ the hip abductor force. A roller boundary condition was applied on the lower edge of the femur stem and the bottom left corner was pinned in the $x$ - and $y$-axes. These three simulations were run to define the stable equilibrium state as being independent of the initial tissue volume fractions and driven by the physiological processes taken into account here (i.e. cellular migration, proliferation, resorption and maturation). Such equilibrium state can be considered as indicative of the overall homeostasis.

\subsubsection{Influence of loading angle and magnitude}

Two further simulations were run to investigate the influence of the loading angle and magnitude on the resulting homeostasis. Both of these simulations were started from an initially uniform tissue distribution where $\varphi^{I}=0.1$ and $\varphi^{M}=0.25$. The loading angle for the first simulation was reduced by $10^{\circ}\left(F_{1}=2317 \mathrm{~N}, \theta_{1}=14^{\circ}\right.$ and $\left.F_{2}=703 \mathrm{~N}, \theta_{2}=18^{\circ}\right)$ and the loading magnitude was reduced for the second simulation $\left(F_{1}=1545 \mathrm{~N}, \theta_{1}=14^{\circ}\right.$ and $F_{2}=469 \mathrm{~N}$, $\theta_{2}=18^{\circ}$ ) (Table 2 - Set 2). Each simulation was simulated for a period of $10,000 \mathrm{~h}$.

\subsubsection{Rate coefficients sensitivity study}

A sensitivity study was undertaken to determine the influence of the rate coefficients of proliferation, resorption, maturation and migration $(\alpha, \beta, \gamma$ and $\Phi)$ on the observed homeostasis state. The values of the biological rate coefficients were increased and decreased one-by-one by a factor of 1.5 from the control values used in the original three homeostasis simulations (Table 2 - Set 3). Each new simulation was run with the original loading magnitudes and angles used in the first simulations $\left(F_{1}=2317 \mathrm{~N}, \theta_{1}=24^{\circ}\right.$ and $F_{2}=703 \mathrm{~N}, \theta_{2}=28^{\circ}$ ) (Fig. $1 \mathrm{a}$ ) for a simulated period of $6000 \mathrm{~h}$. The initial tissue volume fractions were set to $\varphi^{I}=0.1$ and $\varphi^{M}=0.25$ (Table 2 - Set 3 ).

\section{Results}

\subsection{The influence of loading conditions on structural homeostasis}

A homeostasis state for mean mature bone volume fraction of 0.26 was reached for all three variations of initial mature bone volume fractions (Fig. 2). The correlation coefficient describing the distribution of mature bone volume fraction across the femur geometry between each of the three simulations was $>0.9$ after $10,000 \mathrm{~h}$ of simulated time. Video 1 shows the evolution in mature tissue distribution for all three initial conditions and Fig. 1b shows the distribution of normalized Young's modulus $\left(E / E_{\max }\right.$, where

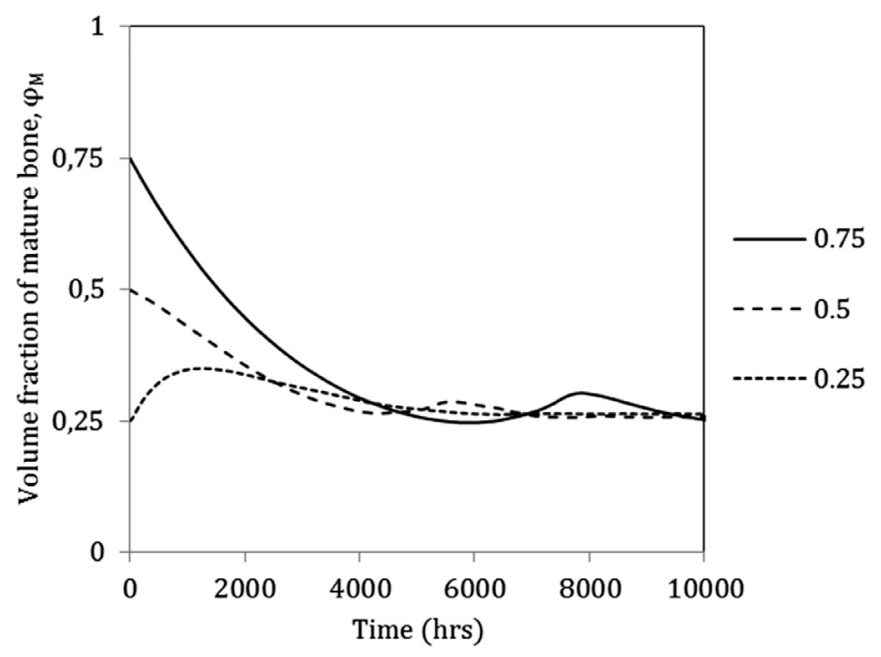

Fig. 2. The mean mature bone volume fraction over the entire femur surface for the three initial mature bone volume fractions $(0.25,0.5$ and 0.75$)$ plotted against time.

$E_{\max }=20 \mathrm{GPa}$ ) after $10,000 \mathrm{~h}$ of simulated time for Set $1 \mathrm{Sim}$ ulation A (Table 2). The homeostasis reached compares favorably with the structurally optimized solution for bone density (Fig. 1c) and roentgenogram (Fig. 1d) from Goda et al. [5]. Regions B and $C$ in Fig. 1b show the qualitatively similar distributions and maximum values of normalized Young's modulus when compared to the same regions from Goda et al. [5]. Region A, however shows a noticeably different pattern of bone tissue distribution and there is not the distinct arch connecting regions $\mathrm{A}$ and $\mathrm{B}$ as was found by Goda et al. [5]. This may be attributable to the different geometries used. In fact, although the angle and intensity of the load used in our study are the same as in Goda et al. [5] (see Table 2, Set 1), the morphology of the two femurs being different (i.e. the neck dimensions, the tilt of the femoral head, etc, Fig. 1a versus Fig. 1c) leads to a different transmission of the efforts throughout the domain.

\subsection{Rate coefficients sensitivity study}

In this section we report the impact of the increase or decrease of the different biological rates (i.e. proliferation, resorption, maturation and migration) on the global response of the model in terms of volume fractions of immature and mature bone.

In Fig. 3a and c, the proliferation rate has no impact on mature bone, whereas it has a noticeably more influential role on the changes in mean immature tissue development, respectively. In fact, after $6000 \mathrm{~h}$ of simulated time the increased and decreased proliferation rates produced mean volume fractions of immature 

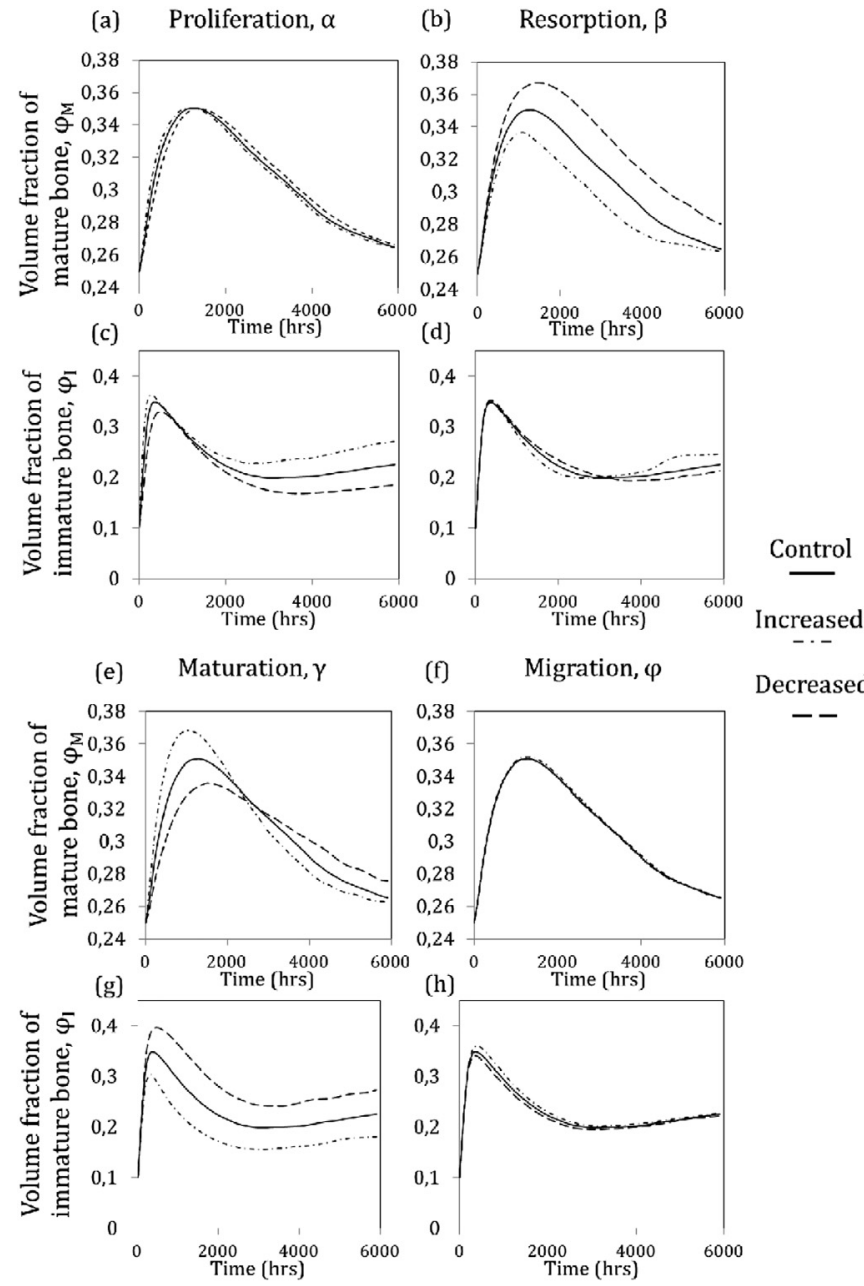

Fig. 3. Plots of the change in the mean mature and immature tissue volume fractions across the femur geometry against time where the rate coefficients of proliferation, resorption, maturation and migration $(\alpha, \beta, \gamma$ and $\Phi)$ have been increase and decreased by a factor of 1.5 from the control value.

tissue of 0.29 and 0.2 , respectively. On the contrary, as can been observed in Fig. 3b and d, resorption rate coefficient has an impact on mature bone, but not on immature tissue.

Regarding the effect of the maturation rate, it can be seen that when the maturation rate is increased, the immature tissue immideatly differentiate in mature tissue, resulting in a lower peak with respect to control for the immature tissue (Fig. $3 \mathrm{~g}$ ) and in a higher peak for the mature tissue (Fig. 3e). The inverse trend is observed when the maturation rate is decreased.

Finally, changing the migration rate does not influence the overall response of both mature and immature bone (Fig. $3 f$ and $h$ ).

\section{Discussion and conclusion}

The influence of mechanical loading on the structure of both cortical and cancellous bone is well documented and intricately linked to the morphological form of bone. However, the coupling of mechanics and biology introduces extra dimensions to the question of bone tissue structural optimization because there is interplay between the biological factors and the mechanically driven architectural optimization. In this work we have applied a mechanobiological model [32] to a proximal femur geometry and demonstrated through FE simulations that the optimized structural distribution of bone tissue is independent of the initial tissue volume fractions and is defined by the loading conditions (Fig. 2). The

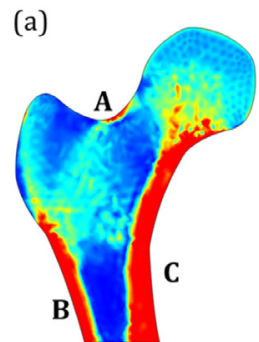

Set $2-A$

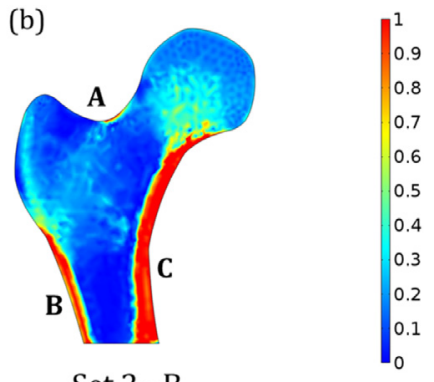

Set 2 - B
Fig. 4. The normalized Young's modulus distribution after $10,000 \mathrm{~h}$ for (a) Decreased loading angle $\theta_{1}-$ Set 2 - Simulation A $\left(F_{1}=2317 \mathrm{~N}, \theta_{1}=14^{\circ}\right.$ and $F_{2}=703$ $\mathrm{N}, \theta_{2}=18^{\circ}$ ) and (b) Decreased loading angle $\theta_{1}$ and decreased loading forces $F_{1}$ and $F_{2}$ - Set 2 - Simulation B $\left(F_{1}=1545 \mathrm{~N}, \theta_{1}=14^{\circ}\right.$ and $\left.F_{2}=469 \mathrm{~N}, \theta_{2}=18^{\circ}\right)$.

homeostasis results compare favorably with previously published structurally optimized bone density distributions [5]. Variations in loading angle and magnitude also demonstrated the sensitivity of the bone architecture to slight loading alterations. This receptiveness to load changes is particularly apparent when considering the seemingly slight adjustment in loading angle of $10^{\circ}$ between Set 1 Simulation A and Set 2 Simulation A (Table 2) (Fig. 4a) and in loading angle and intensity between Set 1 Simulation $A$ and Set 2 Simulation B (Fig. 4b). We observe a striking difference in tissue formation between each simulation at region $A$.

This is only explainable through considering the optimal adaptation of the bone architecture to different loading directions. Another noteworthy factor in comparing our results with those of Goda et al. [5] (Fig. 1c and d) is that the maximum Young's modulus used is $15 \mathrm{GPa}$ compared to $20 \mathrm{GPa}$ in our model. A higher Young's modulus value was chosen in our model because $20 \mathrm{GPa}$ is a more realistic value for the maximum possible Young's modulus of cortical bone $[35,36,38]$. This higher value could explain the differences in cortical thickness and local bone tissue densities seen when comparing the different models.

In addition to the affectability of bone morphology to subtle changes in loading conditions, the influence of the biologically derived rate coefficients has been shown to be significant. The sensitivity study (Fig. 3) demonstrates that the rate of tissue adaptation, when considering the entire proximal femur, is fundamentally controlled by these values. In particular, mature tissue is most influenced by the resorption and maturation coefficients whereas immature tissue is primarily controlled by the proliferation, maturation and slightly by the resorption coefficients. There was little influence detected by the migration coefficient, which may be due to the scaling factor used in the sensitivity study being too low to enact any major shift in remodeling behavior. By describing the intrinsic physiological characteristics being captured by these biological coefficients, it may be possible to identify the structural effects which emerge due to changes in physiology. This is of particular importance when describing and characterizing the effects of physiological ailments, such as bone disorders. The mechano-biological model implemented in this study allows specific adaptations in the biological coefficients to be included in order to capture long term modification in bone properties which cannot be explained by loading variations alone. For example, there is a complex interplay between lifestyle changes (sedentary lifestyle) and physiological alterations (osteoporosis) which impact on bone remodeling behavior and may combine to further deteriorate bone quality and accelerate the negative effects of osteoporosis [28,30,31]. This is evidenced in the results presented in this study where changes in loading angles, loading magnitudes and biological rate coefficients produce alterations in the mature tissue distribution and homeostasis. 
The osteoporosis and osteopetrosis scenarios demonstrate the subtitles involved in capturing the structural effects of long term bone disorders. It is noticeable that there is not a sudden reduction in the overall mature bone tissue content predicted by the osteoporosis case. This may be indicative of the simulation period being too short to capture more long term bone remodeling behaviors. The mechanostat model implemented here uses an accumulated strain feature which integrates the history of previous loading into the model. Because the osteoporosis simulation was initiated from the steady-state conditions reached from Set 1 Simulation A, then there will be a proportion of load memory which would reduce the immediate impact of an increased resorption rate coefficient on the adaptation of the model. This may account for the prolongation of the mature tissue content at a constant level. Alternatively, because the applied loading was not changed between the simulations, then there would be little immediate resorption of tissue in highly strained regions.

Conversely, unlike the mature tissue, the mean immature tissue volume fraction in the osteoporosis scenario is seen to consistently reduce. This finding, brought about by an increased resorption rate (which includes the effect of cellular resorption), may be descriptive of osteoporotic bone having a lowered remodeling capacity or sensitivity to loading changes. Similar behavior has been observed in osteoporotic clinical studies where the bone resorption rate was seen to increased at both the tissue and cellular levels whereas bone formation was unchanged at the tissue level but decreased significantly at the cellular level [39]. In biological terms the reduction in immature tissue observed in the osteoporosis simulation may be considered to be portraying a reduction in cellular activity and subsequent reduced ability to propagate bone formation [39]. A continuation of the trend in immature tissue reduction may lead to a radical decrease in overall immature bone content in the long term, which cannot be captured in a $6000 \mathrm{~h}$ simulation period alone.

The numerical predictions presented in this article may be further advanced by future comparisons with bone healing and formation at the bone implant interface where patient specific inputs may be implemented in order to fully capture the behavior of the remodeling process during the integration of a prosthetic device.

This article demonstrates that the mechanostat model for multi-tissue remodeling [32] may be used to predict the structural optimization of bone tissue for a proximal femur geometry. The results have further provided insights into the adaptation in femur stiffness, tissue distribution and microstructural architectures under varied loading conditions. The biologically derived rate coefficients provide an important link between the overall bone tissue structural optimization and the underlying biology by showing that changes in the rate coefficients, intended to replicate common bone illnesses, produce different steady state optimized structural solutions of bone tissue in the proximal femur geometry.

\section{Acknowledgements}

This work was supported by the Fédération Francilienne de Mécanique (Coup de pouce 2016).

\section{Supplementary materials}

Supplementary material associated with this article can be found, in the online version, at doi:10.1016/j.mechrescom.2018.07. 005.

\section{References}

[1] J.M. García-Aznar, J.H. Kuiper, M.J. Gómez-Benito, M. Doblaré, J.B. Richardson, Computational simulation of fracture healing: influence of interfragmentary movement on the callus growth, J. Biomech. 40 (7) (2007) 1467-1476.
[2] M. Doblaré, J.M. Garcia, M.J. Gomez, Modelling bone tissue fracture and healing: a review, Eng. Fract. Mech. 71 (13-14) (2004) 1809-1840.

[3] V. Klika, M. Angelés, M.J. García-Aznar, F. Maršík, M. Doblaré, Mathematical Biology A coupled mechano-biochemical model for bone adaptation, Math. Biol. 69 (2014) 1383-1429

[4] I. Goda, J.F. Ganghoffer, G. Maurice, Combined bone internal and external remodeling based on Eshelby stress, Int. J. Solids Struct. 94-95 (2015) 138-157.

[5] I. Goda, J.F. Ganghoffer, S. Czarnecki, P. Wawruch, T. Lewiński, Optimal internal architectures of femoral bone based on relaxation by homogenization and isotropic material design, Mech. Res. Commun. 76 (2016) 64-71.

[6] E.G.F. Mercuri, A.L. Daniel, M.B. Hecke, L. Carvalho, Influence of different mechanical stimuli in a multi-scale mechanobiological isotropic model for bone remodelling, Med. Eng. Phys. 38 (9) (2016) 904-910.

[7] T.E. Orr, G.S. Beaupré, D.R. Carter, D.J. Schurman, Computer predictions of bone remodeling around porous-coated implants, J. Arthroplasty 5 (3) (1990) 191-200.

[8] P.J. Prendergast, R. Huiskes, K. Søballe, Biophysical stimuli on cells during tissue differentiation at implant interfaces, J. Biomech. 30 (6) (1997) 539-548.

[9] R. Huiskes, R. Ruimerman, G.H. van Lenthe, J.D. Janssen, Effects of mechanical forces on maintenance and adaptation of form in trabecular bone, Nature 405 (6787) (2000) 704-706.

[10] R. Huiskes, H. Weinans, H.J. Grootenboer, M. Dalstra, B. Fudala, T.J. Slooff, Adaptive bone-remodeling theory applied to prosthetic-design analysis, J. Biomech. $20(11-12)$ (1987) 1135-1150.

[11] H.M. Frost, Perspectives: a proposed general model of the 'mechanostat' (suggestions from a new skeletal-biologic paradigm), Anat. Rec. 244 (2) (1996) 139-147.

[12] C. Lerebours, P.R. Buenzli, S. Scheiner, P. Pivonka, A multiscale mechanobiological model of bone remodelling predicts site-specific bone loss in the femur during osteoporosis and mechanical disuse, Biomech. Model. Mechanobiol. 15 (1) (2016) 43-67.

[13] J. Kular, J. Tickner, S.M. Chim, J. Xu, An overview of the regulation of bone remodelling at the cellular level, Clin. Biochem. 45 (12) (2012) 863-873.

[14] D.P. Byrne, D. Lacroix, P.J. Prendergast, Simulation of fracture healing in the tibia: mechanoregulation of cell activity using a lattice modeling approach, J. Orthop. Res. 29 (10) (2011) 1496-1503.

[15] J. Gao, J.L. Williams, E. Roan, Multiscale modeling of growth plate cartilage mechanobiology, Biomech. Model. Mechanobiol. (2016) 1-13.

[16] X. Liu, G.L. Niebur, Bone ingrowth into a porous coated implant predicted by a mechano-regulatory tissue differentiation algorithm, Biomech. Model. Mechanobiol. 7 (4) (2008) 335-344.

[17] S. Checa, P.J. Prendergast, G.N. Duda, Inter-species investigation of the mechano-regulation of bone healing: comparison of secondary bone healing in sheep and rat, J. Biomech. 44 (7) (2011) 1237-1245.

[18] P.T. Avval, H. Bougherara, Predicting bone remodeling in response to total hip arthroplasty: computational study using mechanobiochemical model, J. Biomech. Eng. 136 (May 2014) (2017) 1-12.

[19] S.V Komarova, R.J. Smith, S.J. Dixon, S.M. Sims, L.M. Wahl, Mathematical mode predicts a critical role for osteoclast autocrine regulation in the control of bone remodeling, Bone 33 (2003) 206-215.

[20] G.S. Beaupré, T.E. Orr, D.R. Carter, An approach for time-dependent bone modeling and remodeling-application: a preliminary remodeling simulation, J. Orthop. Res. 8 (5) (1990) 662-670.

[21] N. Garijo, J.R. Fernández, M.A. Pérez, J.M. García-aznar, Numerical stability and convergence analysis of bone remodeling model, Comput. Methods Appl. Mech. Eng. 271 (2014) 253-268.

[22] M. Doblaré, J.M. García, Anisotropic bone remodelling model based on a continuum damage-repair theory, J. Biomech. 35 (1) (2002) 1-17.

[23] G.S. Beaupré, T.E. Orr, D.R. Carter, An approach for time-dependent bone modeling and remodeling-theoretical development, J. Orthop. Res. (3) (1990) 651-661.

[24] P. Christen, et al., Bone remodelling in humans is load-driven but not lazy, Nat. Commun. 5 (2014) 4855

[25] F.A. Schulte, et al., Local mechanical stimuli regulate bone formation and resorption in mice at the tissue level, PLoS One 8 (4) (2013).

[26] C.L. Donaldson, S.B. Hulley, J.M. Vogel, R.S. Hattner, J.H. Bayers, D.E. Mcmillan, Effect of prolonged bed rest on bone mineral, Metabolism 19 (12) (1970) 1071-1084

[27] P. Mack, P. LaChance, G. Vose, F. Vogt, Bone demineralization of foot and hand of Gemini-Titan IV, V and VII astronauts during orbital flight, Am. J. Roentgenol. radium Ther. Nucl. mdeicine 100 (3) (1967) 503-511.

[28] B.L. Riggs, S. Khosla, L.J. Melton, A unitary model for involutional osteoporosis: estrogen deficiency causes both type I and type II osteoporosis in postmenopausal women and contributes to bone loss in aging men, J. Bone Miner: Res. 13 (5) (1998) 763-773.

[29] C.C. Huang, C.C. Jiang, C.H. Hsieh, C.J. Tsai, H. Chiang, Local bone quality affects the outcome of prosthetic total knee arthroplasty, J. Orthop. Res. 34 (2) (2016) 240-248.

[30] M. Croke, F.P. Ross, M. Korhonen, D.A. Williams, W. Zou, S.L. Teitelbaum, Rac deletion in osteoclasts causes severe osteopetrosis, J. Cell Sci. 124 (22) (2011) $3811-3821$

[31] B. Clarke, S. Khosla, Physiology of bone loss, Radiol. Clin. North Am. 48 (3) (2010) 483-495.

[32] J. Frame, P.-Y. Rohan, L. Corté, R. Allena, A mechano-biological model of multi-tissue evolution in bone, Contin. Mech. Thermodyn. (2017). 
[33] T.J. Martin, E. Seeman, Bone remodelling: its local regulation and the emergence of bone fragility, Best Pract. Res. Clin. Endocrinol. Metab. 22 (5) (2008) $701-722$.

[34] Y. Bala, D. Farlay, P.D. Delmas, P.J. Meunier, G. Boivin, Time sequence of secondary mineralization and microhardness in cortical and cancellous bone from ewes, Bone 46 (4) (2010) 1204-1212.

[35] J.Y. Rho, T.Y. Tsui, G.M. Pharr, Elastic properties of human cortical and trabecular lamellar bone measured by nanoindentation, Biomaterials 18 (20) (Oct. 1997) 1325-1330
[36] H. H. Bayraktar, E. F. Morgan, G. L. Niebur, G. E. Morris, E. K. Wong, and T. M. Keaveny, Comparison of the elastic and yield properties of human femoral trabecular and cortical bone tissue vol. 37, pp. 27-35, 2004

[37] K. Hasegawa, C.H. Turner, D.B. Burr, Contribution of collagen and mineral to the elastic anisotropy of bone, Calcif. Tissue Int. 55 (5) (Nov. 1994) 381-386.

[38] J.Y. Rho, L. Kuhn-Spearing, P. Zioupos, Mechanical properties and the hierarchical structure of bone, Med. Eng. Phys. 20 (2) (Mar. 1998) 92-102.

[39] E. Eriksen, S. Hodgson, R. Eastell, S. Cedel, W.M.O Fallon, B.L. Riggs, Cancellous bone remodeling in type I (Postmenopausal) osteoporosis: quantitative assess ment of rates of formation, resorption, and bone loss at tissue and cellular levels, J. bone Miner. Res. 5 (4) (1990) 311-319. 